\title{
The impact of injector placement on the dose preparation conditions in a gasoline direct injection system
}

Direct fuel injection requires appropriate conditions for proper ignition of the formed mixture. The proper combustion process is shaped by the direct fuel injection, whose parameters vary. Preparation of the dose requires proper injector placement in the combustion chamber. This article focuses on the issue of the injector specific spatial and angular position in order to implement the injection and atomization of the fuel. The injector's pseudo-optimal location has been presented along with several changed positions. The research was conducted as a simulation experiment using AVL FIRE 2017 software. The best position of the injector was selected based on the fuel spraying and injection process indicators. It has been shown that the spatial position has the most impact and the injector placement angle is of secondary importance.

Key words: gasoline direct injection, fuel spraying, simulation software

\section{Introduction}

Internal combustion engines with SI remain the main drives in passenger cars, and their position on the market will strengthen [6]. This trend is influenced by, among others, the current aim to reduce the share of CI engines in passenger cars, due to their negative environmental impact [8], and hybridization of car drives, by combining internal combustion engines with electric motors [7, 10].

The development of internal combustion engines with SI in recent years has focused on downsizing, i.e. increasing the engine's power while maintaining a small engine displacement value. This was enforced due to the apparent fuel economy (shown only in drive tests carried out under laboratory conditions) as well as the tax regulations used in many countries, where the fee for owning or purchasing a car is determined based on its engine's displacement value. Downsizing was achieved by increasing the intake air pressure supplied to the engine (mechanically, with a turbine or with a hybrid solution) and using direct fuel injection into the combustion chamber.

Gasoline direct injection is a solution that is currently very rapidly replacing indirect injection technology in spark ignition engines. The share of these injection systems in new vehicles equipped with SI engines in the US market increased in years $2009-2015$ from $5 \%$ to $46 \%$. It is believed that the share of these engines in all on-road vehicles will reach over $50 \%$ by 2020 [13]. There are many technical solutions for the fuel injection systems for SI engines, which have found commercial applications.

Direct injection allows the creation of a stratified lean fuel-air mixture [9]. There are various ways of shaping the fuel stream during direct injection, but all are aimed at creating a stoichiometric mixture in the vicinity of the spark plug, at the moment of discharge on its electrodes.

One of the methods of shaping the sprayed fuel injection stream is the spray-guided method, which consists of injecting liquid fuel in such a way that the fuel stream creates a stoichiometric mixture in the vicinity of the spark plug without interacting with any other factor aside from air.
Generally, a central position of the spark plug in the combustion chamber is preferred: this choice is motivated by the need to reduce the probability of knocking combustion, occurring when the unburned mixture furthest from the spark gap reaches auto-ignition before the arrival of the flame front. A central position of the spark plug allows a symmetrical propagation of the flame front initiated by the spark, taking a shorter path to extend combustion to the whole unburned mixture before auto-ignition occurs [5].

Injection tests were carried out by Zulkefli and Mansor [14] in relation to hydrogen direct injection. Different positions were analyzed $(0,53$ and $90 \mathrm{deg})$ relative to the cylinder axis. It was found that the best position for the application of hydrogen direct injection in an internal combustion engine is the position of $0^{\circ}$ from the combustion chamber axis. This position gives the largest mixing area and effective mass diffusivity of air and the flame can propagate uniformly for the entire combustion process.

Similar changes regarding the position of the injector are also important in dual fuel engines, in which the injection is carried out directly and indirectly. The influence of the $\mathrm{CNG}$ and $\mathrm{H}_{2}$ injectors position change in the intake manifold was studied by Chintala and Subramanian [4]. It has been found that the proper location of the injector allows for a turbulence change of over $50 \%$, which increases the combustible mixture formation rate. At the same time, the change of the injector position results in a $6 \%$ increase in the thermal efficiency of the engine and 5\% increase for injected fuel pressure change (from 1 to 2 bar).

The influence of the methanol injector placement in a dual-fuel engine (diesel-methanol) was studied by Chen et al [3]. The research consisted of analyzing the change of the injector's distance from the inlet valve in the aspect of, among others, the exhaust emissions. It was found that only the maximum engine load affects changes in the emission value. An increase in $\mathrm{NO}_{\mathrm{x}}$ and soot (FSN - filter smoke number) was observed. The influence of the methanol contribution to $\mathrm{NO}_{\mathrm{x}}$ emission was low: no changes were noted in relation to the other injector positions, and with increasing the proportion of methanol - there was a decrease in $\mathrm{NO}_{\mathrm{x}}$ emissions. No influence of the injector position on the 
emission of carbon monoxide and hydrocarbons was noted regardless of the engine load.

This way of shaping the mixture requires a geometric analysis of the injector setting in the combustion chamber, because it forces the initial conditions of the fuel stream movement. This article is intended to study this relation, to ultimately assess the applicability of such a solution.

\section{Research aim and motivation}

The proposed tests are a part of the study stage on the injection and combustion processes using a direct injection of liquid hydrocarbon fuels [11]. This stage focuses on determining the indicators for engine processes using one direct injection gasoline injector depending on its location in the combustion chamber of the internal combustion engine.

The aim of the research is to determine the optimal spatial position of the injector relative to the spark plug and the angular position of its axis relative to the cylinder axis. The optimal location will be determined as such at which the combustion indicators will reach their highest values. In order to assess the response, the variation of indicators will be performed.

\section{Research methodology}

Simulation tests were carried out using a workstation with AVL Fire 2017.0 software.

In order to examine the impact of the gasoline injector position relative to the combustion chamber, three angular positions of the injector relative to the cylinder axis and nine linear distances of the injector from the spark plug located centrally in the cylinder axis were selected as test parameters. Thus, the analysis results for 27 different injector placement positions were generated.

\subsection{Combustion chamber geometry}

The combustion chamber model is based on an internal combustion engine with geometrical parameters presented in Table 1 .

Table 1. Modeled engine technical data

\begin{tabular}{|l|c|c|}
\hline Parameter & Unit & Value \\
\hline Type & - & $\begin{array}{c}\text { Piston engine, 4-stroke, } \\
\text { spark ignition }\end{array}$ \\
\hline Cylinder number & - & 1 \\
\hline Displacement & $\mathrm{cm}^{3}$ & 385 \\
\hline Compression ratio & - & 10.2 \\
\hline Bore & $\mathrm{mm}$ & 83 \\
\hline Stroke & $\mathrm{mm}$ & 71.2 \\
\hline Speed & $\mathrm{rpm}$ & 2000 \\
\hline
\end{tabular}

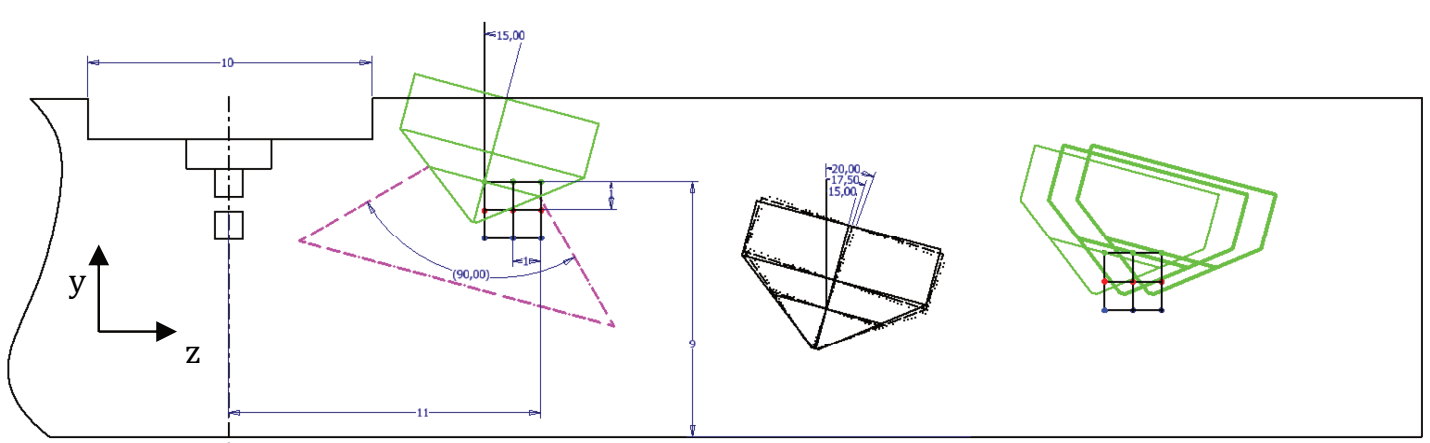

Fig. 2. Diagram of the injector position in relation to the spark plug together with the parameters selected for analysis of injection and combustion (angle, distance) 2017.0 software using the Fame Engine Plus module (Fig. 1), in which the following selections were assigned:

- piston buffer,

- piston moving,

- piston non_moving.

The created mesh of size of 230 thousand cells (Table 2) served as the model for the injection and atomization analysis of gasoline (cell size: $\min : 5 \cdot 10^{-6} \mathrm{~m}$; $\max : 2 \cdot 10^{-3} \mathrm{~m}$ ).

Fuel injection and atomization tests were carried out with an angular resolution of $2 \mathrm{deg}$ on the crankshaft.

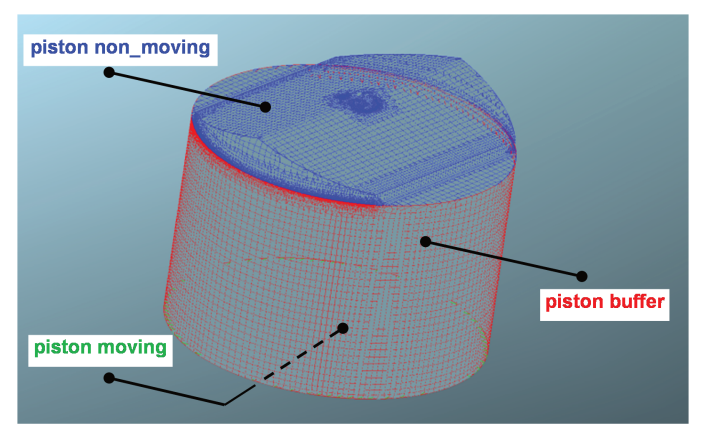

Fig. 1. The displaceable mesh of combustion volume for fuel spray simulation

Table 2. The computational mesh parameters

\begin{tabular}{|l|c|}
\hline Mesh info & Value \\
\hline Number of nodes & 222671 \\
\hline Number of surface faces & 41798 \\
\hline Number of tet cells & 2050 \\
\hline Number of hex cells & 177515 \\
\hline Number of pyramid cells & 16019 \\
\hline Number of prism cells & 34583 \\
\hline Total number of cells & 230167 \\
\hline Surface area & $0.031 \mathrm{~m}^{2}$ \\
\hline Volume & $0.000427 \mathrm{~m}^{3}$ \\
\hline
\end{tabular}

\subsection{Different $y, z$ distances from the spark plug}

The first geometric parameter of the tests is the distance and position of the injector relative to the spark plug. As variables, the distances $\mathrm{y}$ and $\mathrm{z}$ are assumed in accordance with the AVL Fire 2017 coordinate system. The y direction coincides with the axis of the cylinder and the spark plug. The values of the y coordinate change are: 9,10 and 11 $\mathrm{mm}$. The $\mathrm{z}$ coordinate changes are 7,8 and $9 \mathrm{~mm}$. The $\mathrm{x}$ coordinate is constant and equal to 0 , so that placing the injector tip is always in the yz plane. The values of coordinate variables are shown in Fig. 2.
The displaceable mesh was created in the AVL Fire 
Each injector position is described by a code containing the change of position with respect to the y axis, with respect to the $\mathrm{z}$ axis, and the change of angle with respect to the cylinder axis:

$$
\mathrm{y}(\mathrm{i}) \mathrm{z}(\mathrm{j}) \mathrm{alpha}(\mathrm{k})
$$

where: $\mathrm{i}=7 \mathrm{~mm}, 8 \mathrm{~mm}$ and $9 \mathrm{~mm}, \mathrm{j}=9 \mathrm{~mm}, 10 \mathrm{~mm}$ and 11 $\mathrm{mm}$, while $\mathrm{k}=15,17.5$ and $20 \mathrm{deg}$.

\subsection{Different injector placement angles}

Another one of the geometrical parameters tested is the yaw angle of the injector axis with respect to the cylinder axis. Because of the different position of the injector relative to the cylinder (a spark plug is located in the cylinder axis, this is expected due to the end design solution - two injectors placed in the combustion chamber) the change in the angle of the injector axis relative to the cylinder axis is necessary. Three values were used to determine the effect of this angle on the dose mixture preparation process: 15 deg, $17.5 \mathrm{deg}$ and $20 \mathrm{deg}$ (Fig. 1).

\subsection{Modeling the fuel injection}

Fuel injection started at an angle of $670 \mathrm{deg}$ and lasted $0.6 \mathrm{~ms}$. The fuel dose was $13.1 \mathrm{mg}$, which corresponded to the value of the excess air ratio $\lambda=1$.

The Schiller-Naumann drag law model $\mathrm{C}_{\mathrm{d}}$ is an empirically evaluated equation for calculating the drag coefficient in drag force acting on the flowing particles in fluid with $\mathrm{Re}$ ranging from 0.2 to 1000 . It is described with the equation:

$$
\mathrm{C}_{\mathrm{d}}=24 / \operatorname{Re}\left(1+0.15 \operatorname{Re}^{0.687}\right)
$$

where $R e$ is the Reynolds number. For the $\operatorname{Re}>1000$ the $C_{d}$ has the constant value of 0.44 [6].

Fuel injection is based on the atomization of droplets taking into account the KH-RT model. The model of KelvinHelmholtz and Rayleigh-Taylor, which is a development of the Reitz-Diwakar model made by Reitz, is based on a linear analysis of instability which results in a dispersion equation determining the rate of initial surface disturbance in relation to the wavelength. Surface waves in the Kelvin-Helmholtz model $(\mathrm{KH})$ and disturbances in the Rayleigh-Taylor model (RT) determine the distribution of droplets. These models differ in their approach to creating new droplets.

The new model takes into account the change in weight and the formation of droplets with smaller diameters. As a result, more smaller drops are obtained. The $\mathrm{KH}$ model is used when there are high flow rates and high density of the medium, and the RT model is used when the drops are slowed down rapidly, resulting in increased surface waves at the stop point of the droplets. This means that it is mainly used for high pressure injection (also of gasoline). Some authors [12] use this model to study direct injection of gasoline from multi-hole injectors supplied at a pressure of 7.5-12 MPa.

The following coefficient values were adopted in this model: $\mathrm{C}_{1}=0.61 ; \mathrm{C}_{2}=12 ; \mathrm{C}_{3}=10 ; \mathrm{C}_{4}=5.33 ; \mathrm{C}_{5}=1 ; \mathrm{C}_{6}=$ $=0.3 ; C_{7}=0.05 ; C_{8}=0.188[6]$.

$\mathrm{C}_{1}$ is a $\mathrm{KH}-\mathrm{WAVE}$ model constant to adjust stable droplet radius according to the formula:

$$
\mathrm{R}_{\mathrm{a}}=\mathrm{C}_{1} \Lambda
$$

where $R_{a}$ is a KH-WAVE model droplet radius, and $\Lambda$ is a wave length function depending on the Weber's number of the continous phase and Ohnesorge's number of the droplet.

$\mathrm{C}_{2}$ is a KH-WAVE model constant to adjust break-up time according to the formula:

$$
\tau_{\mathrm{a}}=\frac{3.7 \mathrm{C}_{2} \mathrm{R}}{\Lambda \Omega}
$$

where $\mathrm{R}$ is a droplet radius, and $\Omega$ is a break-up frequency function depending on the Weber's number of the continous phase and Ohnesorge's number of the droplet.

$\mathrm{C}_{3}$ is a type constant to adjust break-up length according to the formula:

$$
\mathrm{L}=\mathrm{C}_{3} \sqrt{\frac{\rho_{\mathrm{d}}}{\rho_{\mathrm{c}}}} \mathrm{d}_{0}
$$

where $\rho_{\mathrm{d}}$ is a droplet density, $\rho_{\mathrm{c}}$ is a continous phase density and $\mathrm{d}_{0}$ is a initial droplet diameter.

$\mathrm{C}_{4}$ is an RT model constant to adjust wave length according to the formula:

$$
\Lambda=\mathrm{C}_{4} \frac{\pi}{\mathrm{K}_{\mathrm{t}}}
$$

where $K_{t}$ is a wave number assessed via:

$$
K_{t}=\sqrt{\frac{g_{t}\left|\rho_{d}-\rho_{c}\right|}{3 \sigma}}
$$

where $\sigma$ is a droplet surface tension and $g_{t}$ is an deceleration of the droplet in the direction of travel.

$\mathrm{C}_{5}$ is an RT model constant to adjust break-up time according to the formula:

$$
\tau_{\mathrm{t}}=\mathrm{C}_{5} \frac{1}{\Omega_{\mathrm{t}}}
$$

where $\Omega_{\mathrm{t}}$ is a break-up frequency assessed via:

$$
\Omega_{\mathrm{t}}=\sqrt{\frac{2}{3 \sqrt{3} \sigma} \frac{\mathrm{g}_{\mathrm{t}}\left|\rho_{\mathrm{d}}-\rho_{\mathrm{c}}\right|^{1.5}}{\rho_{\mathrm{d}}+\rho_{\mathrm{c}}}}
$$

$\mathrm{C}_{6}$ determines the fraction of the parcel volume which has to be detached until child parcels are initialized. Its value is within the range from 0.1 to 0.5 .

$\mathrm{C}_{7}$ determines the fraction of the shed mass which is finally transformed into child parcels. Its value is within the range from 0.01 to 0.3 .

$\mathrm{C}_{8}$ is a constant to adjust droplet normal velocity according to the formula:

$$
\mathrm{V}_{\text {norm }}=\mathrm{C}_{8} \Lambda \Omega
$$

\subsection{Evaporation modeling}

The Dukowicz evaporation model describes the heat and mass transfer processes impact on the droplet-fluid border. The model is based on the following assumptions [1]:

- spherical symmetry,

- quasi steady gas-film around the droplet,

- uniform droplet temperature along its diameter,

- uniform physical properties of the surrounding fluid,

- liquid-vapor thermal equilibrium on the droplet surface.

The following coefficient values have been used in the model: $\mathrm{E}_{1}=2 ; \mathrm{E}_{2}=2$. $\mathrm{E}_{1}$ is a heat transfer multiplicative factor and $E_{2}$ is a mass transfer multiplicative factor; both act on the transfer coefficient [1]. 
4. Impact of injector placement on fuel atomization conditions

Various injector positions were analyzed in terms of changes to: mass of evaporated fuel, mass of remaining (unevaporated) fuel, diameter of fuel droplets, turbulence kinetic energy, dissipation of energy and excess air ratio.

Figure 3 presents the results of fuel atomization analysis taking into account the change of the injector's position in the direction of the y axis (according to Fig. 2). The most advantageous position is far in the combustion chamber (reduction of the y coordinate). In this position (value $y=7 \mathrm{~mm}$ ), the amount of vaporized fuel is the highest at a constant crankshaft angle (analysis was done for the angle $690 \mathrm{deg}$ ).

This is due to the proper distance of the injector from the spark plug electrodes. This injector position prevents the fuel stream from reaching the spark plug electrode and allows to increase the fuel evaporation. The extreme positions of the injector along the variable y (position changes in relation to the cylinder axis) relative to the solution adopted $(\mathrm{y}=7 \mathrm{~mm}$ ) result (at a crankshaft angle of 690 deg) in:

- increasing the evaporated fuel mass by $7.4 \%$;

- decreasing the unevaporated fuel mass by $18.9 \%$;

- reducing the droplet diameter by $2.6 \%$;

- increasing the turbulence kinetic energy by $7.1 \%$;

- increasing the energy dissipation by $17.7 \%$;

- increasing the excess air ratio by $7.5 \%$.

Changes in the position of the injector relative to the $\mathrm{z}$ axis (distance from the spark plug) do not cause such large changes in the indicators analyzed above (Fig. 4). The best solution is the location ( $\mathrm{z}=9 \mathrm{~mm})$, because the evaporated fuel mass is the largest. The extreme position of the injector along the variable $\mathrm{z}$ (position changes in relation to the cylinder axis) with respect to the adopted solution $(z=9$ $\mathrm{mm}$ ) results (at an angle of $690 \mathrm{deg}$ ) in:
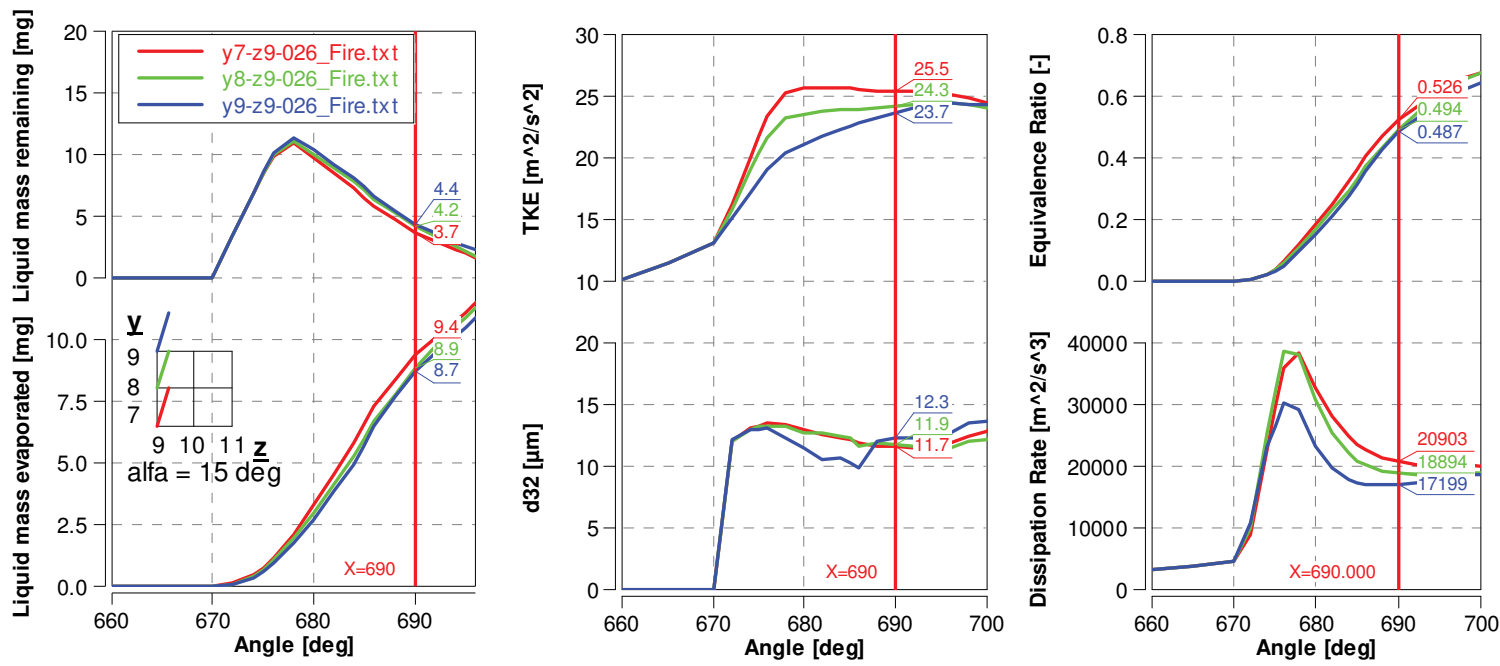

Fig. 3. Impact of the injector position change in the combustion chamber - y coordinate (changes in the injector placement height in the combustion chamber)
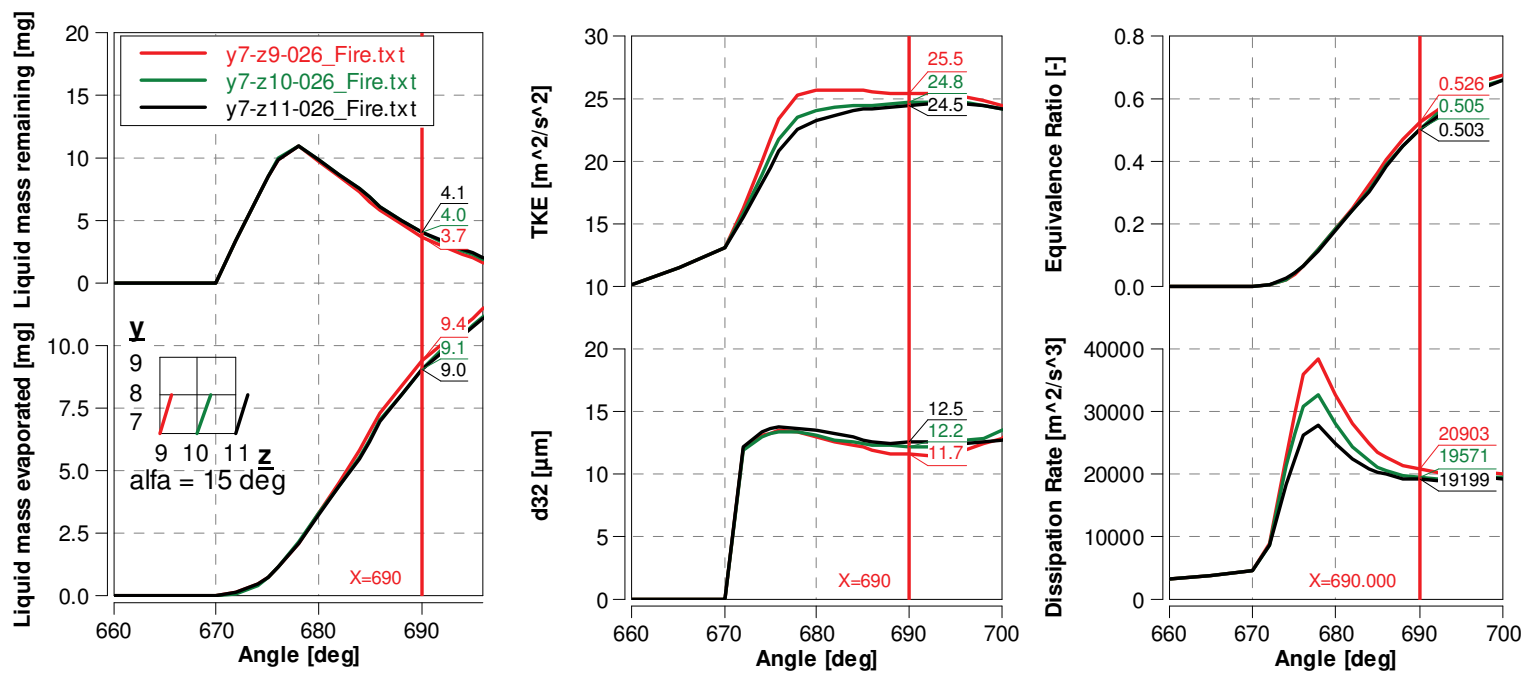

Fig. 4. Impact of the injector position change in the combustion chamber - coordinate $\mathrm{z}$ (changes of the injector distance from the spark plug in the com-

- increasing the evaporated fuel mass by $4.3 \%$;

- decreasing the unevaporated fuel mass by $10.8 \%$;

- reducing the droplet diameter by $6.8 \%$; bustion chamber)

- increasing the turbulence kinetic energy by $3.9 \%$;

- increasing the energy dissipation by $8.2 \%$;

- $\quad$ increasing the excess air ratio by $4.4 \%$. 
The smallest change of the angular position of the injector (in relation to changes in y and $\mathrm{z}$ ) leads to changes in the analyzed indicators (Fig. 5). The best solution is the angular position alpha $=15 \mathrm{deg}$, because the mass of evaporated fuel is the largest. Extreme positions of the injector (changes of the angular position) relative to the adopted solution (alpha $=15 \mathrm{deg}$ ) result (at an angle of $690 \mathrm{deg}$ ) in:
- increasing the evaporated fuel mass by $1.1 \%$;

- decreasing the unevaporated fuel mass by $2.7 \%$;

- reducing the droplet diameter by $2.6 \%$;

- no change in the turbulence kinetic energy;

- increasing the energy dissipation by $0.1 \%$;

- increasing the excess air ratio by $1.1 \%$.
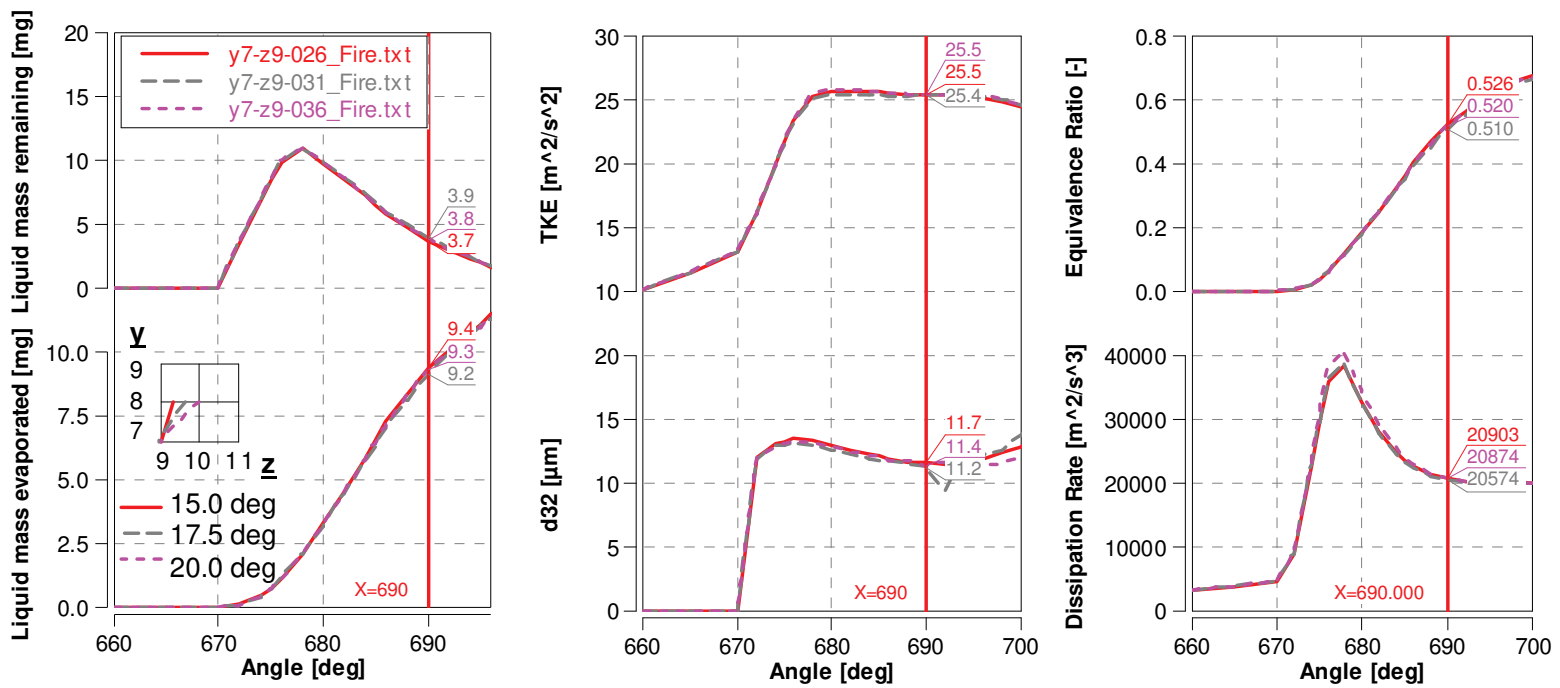

Fig. 5. Impact of the change of the injector position in the combustion chamber - alpha angle

$\alpha[\operatorname{deg}]$

$$
\mathrm{z}=9 \mathrm{~mm}
$$

$\mathrm{z}=10 \mathrm{~mm}$

$\mathrm{z}=11 \mathrm{~mm}$

675
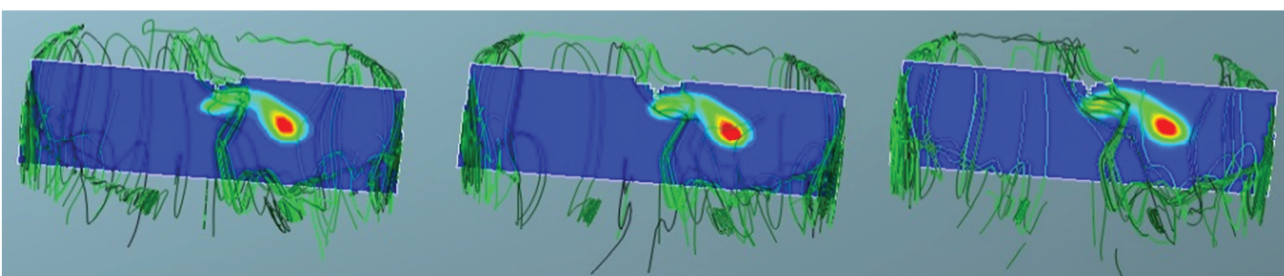

680
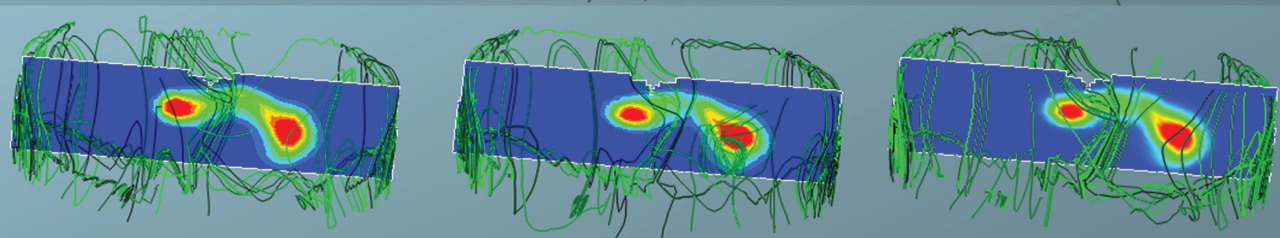

685
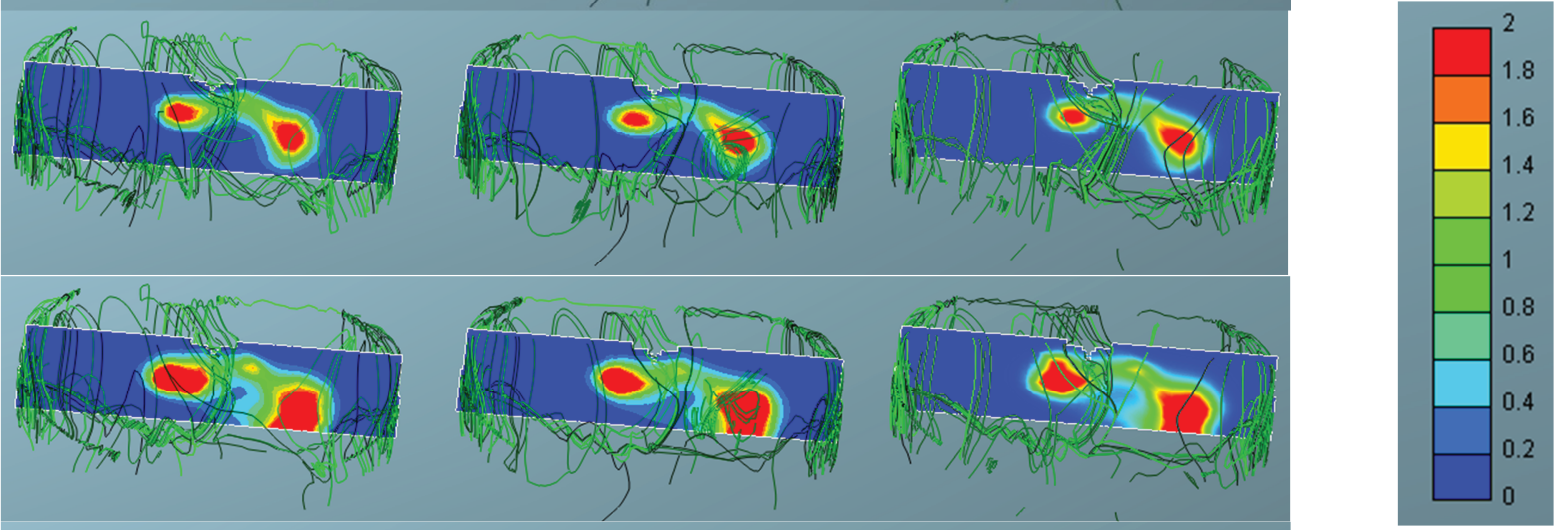

690
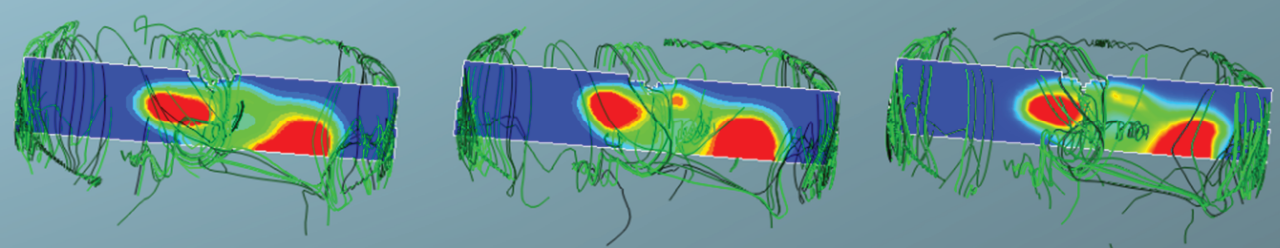

Fig. 6. Distribution of factor $1 / \lambda$ in the combustion chamber for different positions of the injector with respect to the $\mathrm{z}$ axis (position code $y(7) z(i) a l p h a(15)$, where $i=9,10,11$, which means $y=7 \mathrm{~mm}$, alpha $=15^{\circ}$ )

The results of local fuel atomization processes were also helpful in further analysis. The distribution of the equiva- lence coefficient $(1 / \lambda)$ indicates its sensitivity to the injector location in the combustion chamber (Fig. 6). The figure 
shows three different injector positions relative to the $\mathrm{z}$ axis. Changing the position of the injector (its offset from the injector, thus increase in the $\mathrm{z}$ coordinate) results in a differentiation of the excess air coefficient around the spark plug. Excess air of 1 in the vicinity of the plug is limited by area. A tendency that remains present independent of the crankshaft angle.

Figure 7 shows the excess air coefficient constant value isosurface for gasoline injection depending on the angle of the crankshaft rotation at different $\mathrm{z}$-coordinate values.

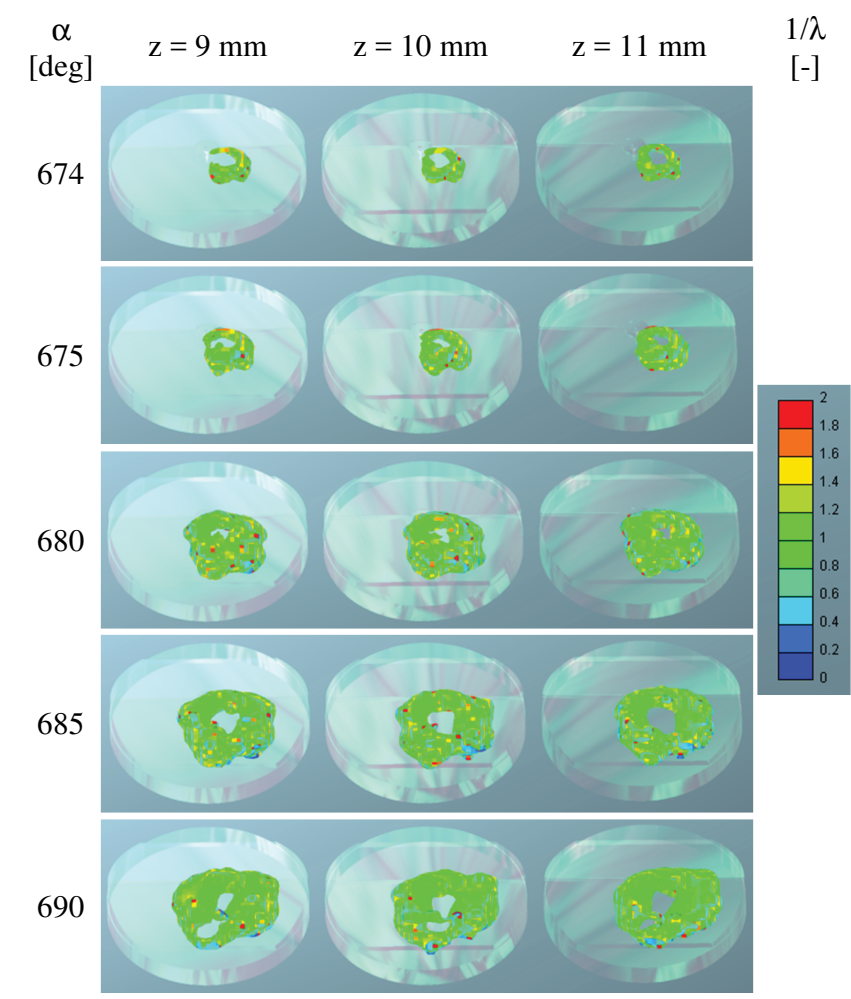

Fig. 7. Constant value isosurface $\lambda=1$ on the combustion chamber background at various injector positions with respect to the $\mathrm{z}$ axis (position code $y(7) z(i) a l p h a(15)$, where $i=9,10,11$, which means $y=7 \mathrm{~mm}$, alpha $\left.=15^{\circ}\right)$
The presented isosurface indicate that a proper injector location results in specific effects in the development of the fuel dose in the combustion chamber. Due to the varied positioning of the injector, it is possible to choose the solution that is most advantageous in terms of fuel injection and atomization.

The different positioning of the injector also affects changes in the turbulence kinetic energy (TKE), which is responsible for the mixing of fuel and air. Its increase is observed during the fuel delivery from an injector located closer to the spark plug axis (Fig. 8). It follows that the closer position of the injector with respect to the spark plug results in a better fuel atomization and its mixing with the air, and thus such position allows to increase the evaporation of fuel.

\section{Comparative analysis of the injector placement in the combustion chamber}

First, the mass of evaporated fuel was determined for all injector positions relative to the angle of its location (Fig. 9a) at the engine's working angle of $690 \mathrm{deg}$. The comparison indicates that the largest mass of evaporated fuel is does not occur at the same injector position at each one of its placement angles. The highest values of evaporated fuel were obtained at the location coordinates of $y(7) z(9)$ alpha(15) and $y(7) z(9)$ alpha(20) - which means $y=$ $7 \mathrm{~mm}$ and $\mathrm{z}=9 \mathrm{~mm}$ at the angles of 15 and $20 \mathrm{deg}$. However, at an angle of $17.5 \mathrm{deg}$, the best option was to place the injector at the coordinates $\mathrm{y}=7$ and $\mathrm{z}=11$ (code $y(7) z(11) \operatorname{alpha(17.5)).~}$

Analysis of the average excess air ratio in the combustion chamber (at an angle of $690 \mathrm{deg}$ ) shows similar tendencies (Fig. 9b) to previous considerations. The largest values of the global excess air ratio were obtained for the same sequences.

These considerations prompted the authors to determine the best injector position through pseudo-optimization. With the obtained values of evaporated fuel mass, diameter of fuel droplets, turbulence kinetic energy, dissipation of energy, excess air ratio and the average temperature in the combustion chamber at an angle of $690 \mathrm{deg}$ on the crankshaft, the data was scaled.

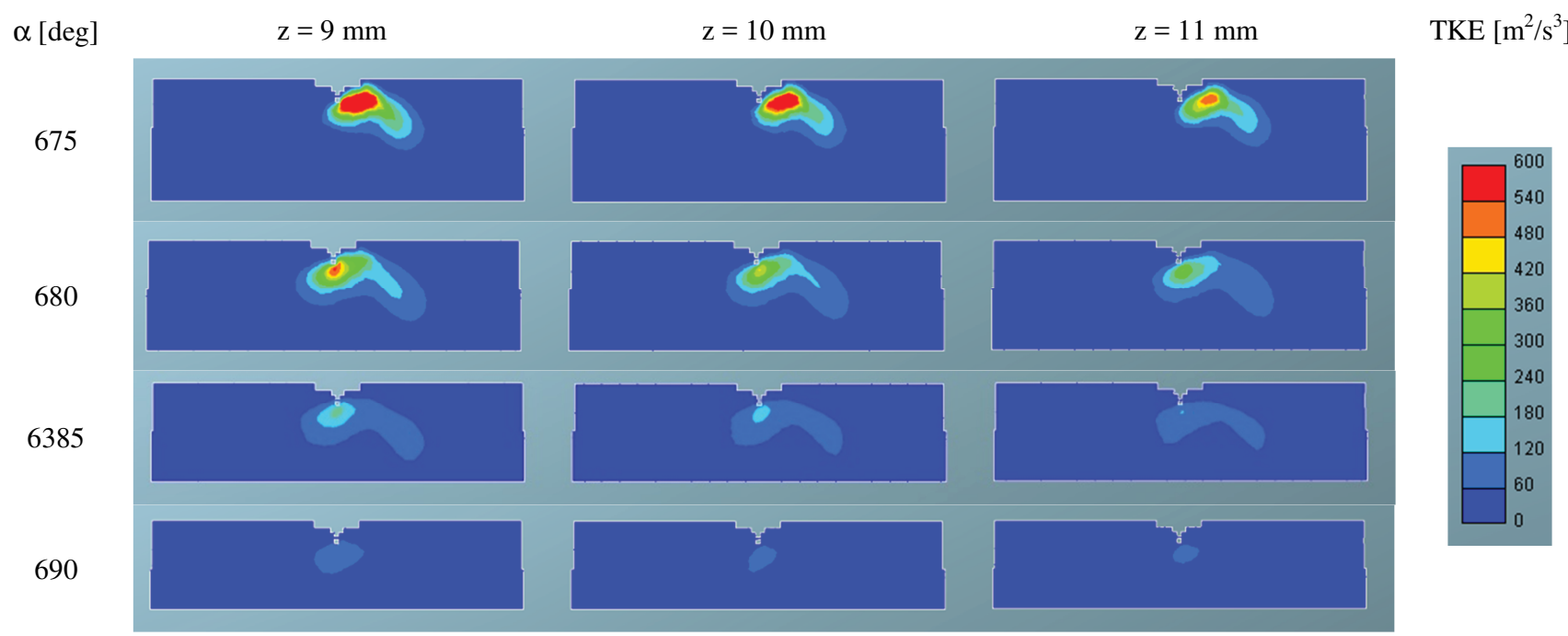

Fig. 8. TKE changes at different injector positions relative to the $\mathrm{z}$ axis (location code $\mathrm{y}(7) \mathrm{z}(\mathrm{i}) \mathrm{alpha}(15)$, where $\mathrm{i}=9$, 10, 11, which means $\mathrm{y}=7 \mathrm{~mm}$, alpha $\left.=15^{\circ}\right)$ 
a)
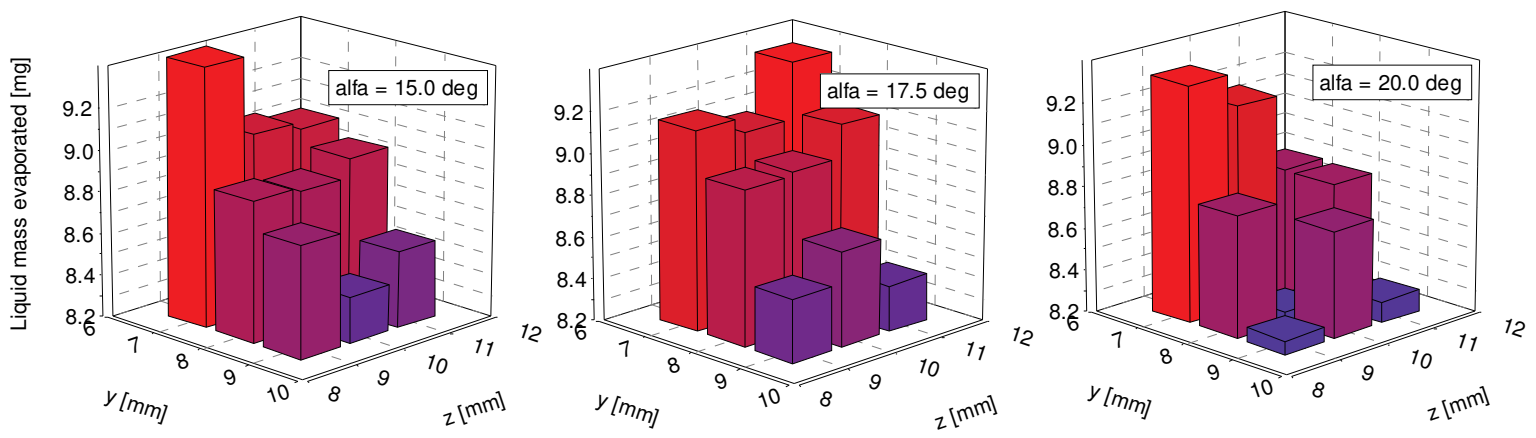

b)
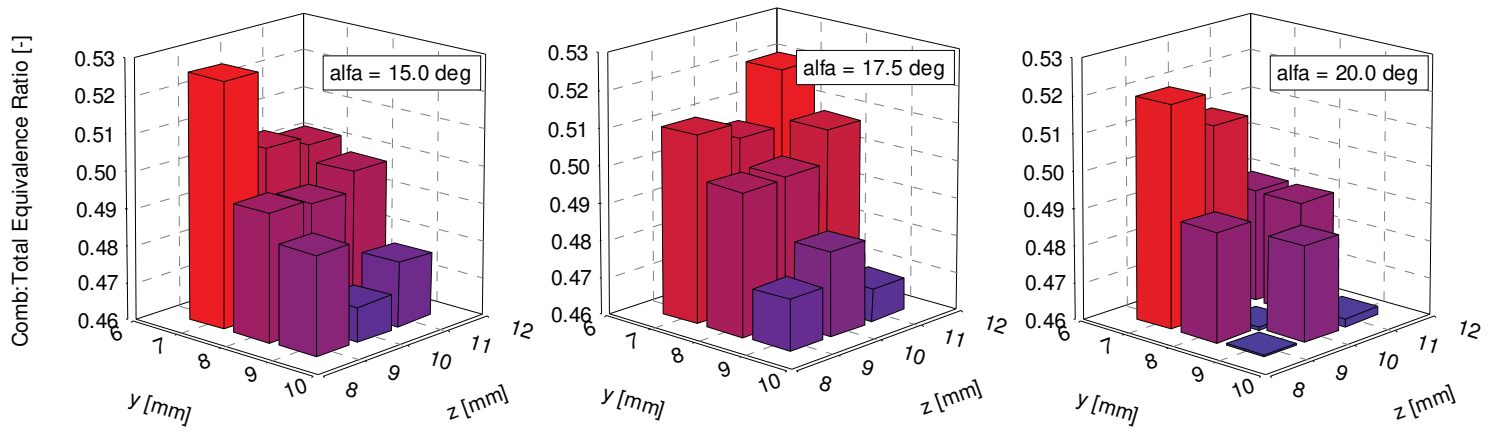

Fig. 9. Changes in fuel atomization indicators: a) weight of evaporated fuel, b) equivalence ratio (1/lambda) at various injector positions in the combustion chamber

Thus the following values have been used:

- the best value for a given indicator to take (the largest mass of evaporated fuel, smallest droplet diameter, the smallest energy dissipation, the largest TKE, the smallest equivalence factor - the largest value of excess air ratio and the highest temperature of the fuel dose) that can be obtained is equal to 1 ;

- the worst possible indicator value is 0 .

The scaling was performed on this basis, and the results are presented in Table 3. The values of particular indicators have been assigned to each of the injector's positions.

Table 3. Relative values of fuel atomization and conditions present in the combustion chamber at individual injector positions

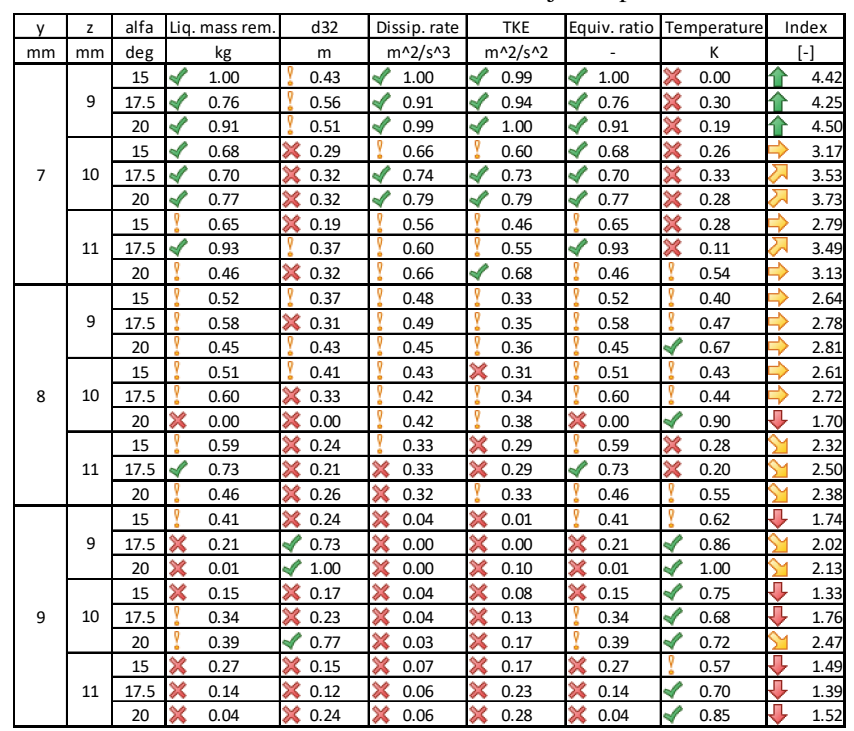

Changes in these values occur in the range of $<0 ; 1>$. The table also contains a pictogram analysis, which shows that the most positive results occur when placing the injector at the coordinates $\mathrm{y}=7 \mathrm{~mm}$ and $\mathrm{z}=9 \mathrm{~mm}$ or $\mathrm{z}=10$ $\mathrm{mm}$. The worst position of the injector is the one with the $y$ coordinate of $\mathrm{y}=9 \mathrm{~mm}$.

Due to the fact that it was still impossible to determine the best injector position, the normalized values of process indicators were summed for each of the injector positions (Fig. 10). Using such a summation method, the maximum possible value is 6 (when all normalized indicator values obtained were equal to 1 ). The highest value of 4.50 normalized indicators was obtained for the injector position with the co-ordinates $y=7, z=9$ and the angle alpha $=20 \mathrm{deg}$ (code: $y(7) z(9)$ alpha(20)), as shown in the column titled "Index" in Table 3. It should be noted, however, that all the injector angular positions at $y=7$ and $z=9$ (closest to the spark plug) obtained the highest values of the normalized sums.

Additionally, in Fig. 10, the sums of normalized fuel atomization indicators are summarized (sum of the "Index" column for individual injector positions). They were calculated as follows:

$$
\begin{aligned}
y(7 \mathrm{~mm}) & =\Sigma y(7) z(j) \operatorname{alpha}(k) \\
y(8 \mathrm{~mm}) & =\Sigma y(8) z(j) \operatorname{alpha}(k) \\
y(9 \mathrm{~mm}) & =\Sigma y(9) z(j) \operatorname{alpha}(k) \\
z(9 \mathrm{~mm}) & =\Sigma y(i) z(j) \operatorname{alpha}(k) \\
z(10 \mathrm{~mm}) & =\Sigma y(i) z(j) a l p h a(k) \\
z(11 \mathrm{~mm}) & =\Sigma y(i) z(j) a l p h a(k) \\
\text { alpha(15 deg }) & =\Sigma y(i) z(j) a l p h a(15)
\end{aligned}
$$


alpha $(17.5 \mathrm{deg})=\Sigma \mathrm{y}(\mathrm{i}) \mathrm{z}(\mathrm{j}) \mathrm{alpha}(17,5)$

$$
\text { alpha(20 deg })=\Sigma y(i) z(j) a l p h a(20)
$$

where: $\mathrm{i}=7 \mathrm{~mm}, 8 \mathrm{~mm}$ and $9 \mathrm{~mm}, \mathrm{j}=9 \mathrm{~mm}, 10 \mathrm{~mm}$ and 11 $\mathrm{mm}$, while $\mathrm{k}=15,17.5$ and $20 \mathrm{deg}$.

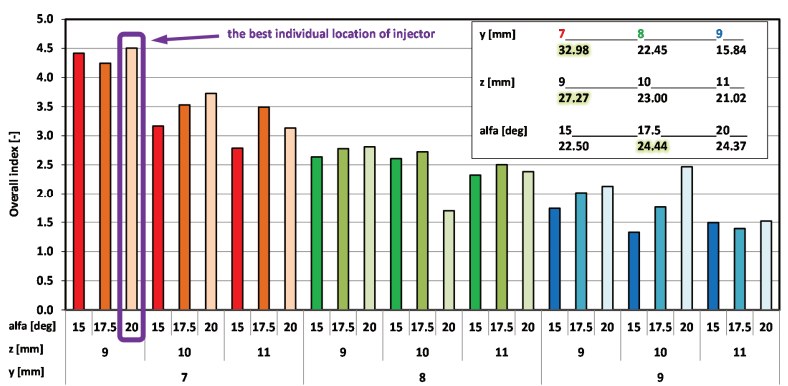

Fig. 10. Indicators of the best injector position selection based on selected quantities regarding fuel injection conditions (based on Table 1)

The performed comparison leads to the conclusion that the highest point value was obtained for the injector position $\mathrm{y}=7 \mathrm{~mm}$. This means that fuel atomization indicators take the highest values at this injector position, regardless of the other position variables. This position with the changing variable $\mathrm{z}$ is $9 \mathrm{~mm}$. Although the best angular position turned out to be $20 \mathrm{deg}(\operatorname{code} \mathrm{y}(7) \mathrm{z}(9)$ alpha(20) at $\mathrm{y}=7$ and $\mathrm{z}=9 \mathrm{~mm})$, the best results were obtained at an angle of $17.5 \mathrm{deg}$ without taking into account the $\mathrm{y}$ and $\mathrm{z}$ coordinates.

The injector position change sensitivity range was determined to be:

$$
\begin{gathered}
\text { delta } y= \\
0.5(\max (y(i) z(j) a l p h a(k))-\min (y(i) z(j) \text { alpha }(k)))
\end{gathered}
$$

where the values $\max ()$ and $\min ()$ can be found in Table 3 .

The results of these calculations are presented in Fig. 11. It follows that the results are most sensitive to the $y$ coordinate injector position change - the height of the injector position. Another variable determining the total index sum value (expressed in numerical form in Fig. 10) is the change in distance from the axis of the spark plug. The least sensitive parameter for changes in fuel atomization indicators is the injector position angle within the limits adopted for the performed simulation tests.

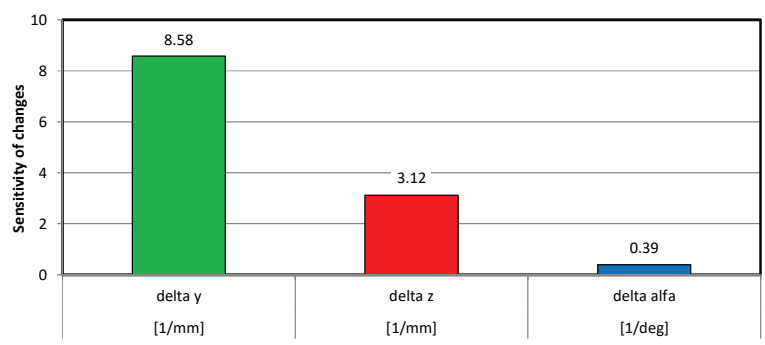

Fig. 11. The impact of changes in the size of the $y, z$ and angle values of the injector in the combustion chamber

\section{Conclusions}

Injector location tests were conducted using computer simulation, which were used to analyze the fuel atomization indicators before ignition. The best solution was defined as one which, as a result of normalizing the indicators, allowed to obtain the largest value of the sum of all these indicator values.

The pseudo-optimal location (within the adopted model boundaries), was characterized by:

- the largest inset in the combustion chamber $\mathrm{y}=7 \mathrm{~mm}$,

- the shortest distance from the spark plug $\mathrm{z}=9 \mathrm{~mm}$,

- the highest angle in relation to the axis of the cylinder alpha $=20 \mathrm{deg}$.

The differences in the indicator values between the maximum changes in the injector inset in the combustion chamber were:

- $7.4 \%$ evaporated fuel mass;

- $18.9 \%$ unevaporated fuel mass;

- $2.6 \%$ droplet diameter;

- $7.1 \%$ turbulence kinetic energy;

- $17.7 \%$ energy dissipation;

- $7.5 \%$ excess air ratio.

The differences in the indicator values between the maximum changes in the injector distance from the spark plug were:

- $4.3 \%$ evaporated fuel mass;

- $10.8 \%$ unevaporated fuel mass;

- $6.8 \%$ droplet diameter;

- $3.9 \%$ turbulence kinetic energy;

- $8.2 \%$ energy dissipation;

- $4.4 \%$ excess air ratio.

The differences in the indicator values between the maximum changes in the injector angle relative to the cylinder axis were:

- $1.1 \%$ evaporated fuel mass;

- $2.7 \%$ unevaporated fuel mass;

- $2.6 \%$ droplet diameter;

- $0.0 \%$ turbulence kinetic energy;

- $0.1 \%$ energy dissipation;

- $1.1 \%$ excess air ratio.

Sensitivity of changes in the injector position was determined on the basis of the total indicator sum of changes in a given coordinate or angle (Fig. 11). The analysis of this sensitivity results in the following conclusions:

- the longitudinal change of the injector position is the most important value affecting changes in the fuel atomization indicators;

- this change is about 3 times more significant than the change in the position of the injector's distance from the axis of the spark plug and about 15 times more significant than the angle of the injector's position.

The conclusions obtained after the simulation analysis of the phenomenon will be taken into account in comparison of fuel atomization rates in the two injectors system and during combustion analyzes of both systems - with one and two injectors. The presence of a fuel stream from the second injector may be particularly significant, as Borowski demonstrated [2]. The second fuel stream will change the size of the turbulence and the associated with it mass of vaporized fuel.

\section{Acknowledgements}

The study presented in this article was performed within the statutory research (contract No. 05/52/DSMK/0265). 


\section{Nomenclature}

C coefficient value (injection model)

CI compression ignition

CNG compressed natural gas

$\mathrm{d}_{32} \quad$ Sauter mean diameter

$\mathrm{d}_{0} \quad$ initial droplet diameter

E coefficient value (evaporating model)

FSN Filter Smoke Number

$\mathrm{g}_{\mathrm{t}}$ deceleration of the droplet

$\mathrm{H}_{2}$ hydrogen

KH Kelvin-Helmholtz model

LPG liquified petrolum gas

$\mathrm{NO}_{x}$ nitrogen oxide

$\mathrm{R}_{\mathrm{a}} \quad$ stable droplet radius

Re Reynolds number

RT Rayleigh-Taylor model

$\begin{array}{ll}\text { SI } & \text { spark ignition } \\ \text { TKE } & \begin{array}{l}\text { turbulence kinetic energy } \\ \text { coordinate }(0)\end{array} \\ \mathrm{y} & \begin{array}{l}\text { coordinate (direction coincides with the axis of the } \\ \text { cylinder and the spark plug) }\end{array} \\ \mathrm{z} & \begin{array}{l}\text { coordinate (direction coincides with the radial axis } \\ \text { of the cylinder) }\end{array} \\ \text { alpha } & \text { angular position } \\ \rho_{\mathrm{c}} & \text { continuous phase density } \\ \rho_{\mathrm{d}} & \text { droplet density } \\ \Lambda & \text { wave length function } \\ \lambda & \text { lambda value } \\ \sigma & \text { droplet surface tension }\end{array}$

[8] MERKISZ, J., PIELECHA, J. Nanoparticle emissions from combustion engines. Springer Tracts on Transportation and Traffic, Springer International Publishing Switzerland, 2015, 8.

[9] PIELECHA, I. A study of direct multiple gasoline injection and combustion in terms of control of the engine processes. Series of the dissertations. No. 473, Publishing House Poznan University of Technology, Poznan 2012.

[10] PIELECHA, I., CIEŚLIK, W., SZAŁEK, A. Operation of hybrid propulsion systems in conditions of increased supply voltage. International Journal of Precision Engineering and Manufacturing. 2017, 18(11), 1633-1639. doi.org/10.1007/ s12541-017-0192-3.

[11] SIDOROWICZ, M., PIELECHA, I. Inflammability evaluation of hydrocarbon fuels mixtures formed directly in the combustion chamber. Combustion Engines. 2017, 170(3), 57-65. doi:10.19206/CE-2017-309.

12] YI, Y., DEMINCO, C. Numerical investigation of mixture preparation in a GDI engine. SAE Technical Paper 2006-013375, 2006, doi:10.4271/2006-01-3375.

[13] ZIMMERNAM, N., WANG, J.M., JEONG, C.-H. et al. Assessing the climate trade-offs of gasoline direct injection engines. Environmental Science \& Technology. 2016, 50, 8385-8392, doi:10.1021/acs.est.6b01800.

[14] ZULKEFLI, M.H., MANSOR, M.R.A. The effect of injector position on direct injection hydrogen engine conditions. Journal of Engineering Science and Technology. Special Issue on $4^{\text {th }}$ International Technical Conference 2014, 2015, 55-61.

Ireneusz Pielecha, DSc., DEng. - Faculty of Machines and Transport at Poznan University of Technology.

e-mail: Ireneusz.Pielecha@put.poznan.pl 